\title{
Increase in child abuse injuries during the COVID-19 Pandemic in West Texas
}

\author{
Hector Garcia MEng, Thomas G. Wyatt DO, Amber Tucker MSN, RN, Sharmila Dissanaike MD
}

\begin{abstract}
The COVID-19 pandemic led to a rapid increase in unemployment and business closures, leaving many families in psychosocial distress and putting the well-being and healthy development of children at risk. There was a sharp increase in cases of child abuse presenting to our institution during the year 2020. Thus, we sought to determine whether the confluence of pandemic-related social changes would result in an increase in child abuse cases severe enough to warrant emergency medical attention in the West Texas region. Compared to the period of 2015-2019, there were 5 deaths in 2020, which exceeded the total number in past five years combined. Consistent with the previous five years, children under 1 year of age represented the largest proportion of child abuse cases, at 58\%. This report underscores the need for continued vigilance by healthcare providers and educators in identifying cases of child abuse, as well as the need for additional initiatives to mitigate child maltreatment during times of socioeconomic stress.
\end{abstract}

Keywords: Child abuse, COVID-19 pandemic, West Texas, psychological stress

\section{INTRODUCTION}

Indirect consequences of the COVID-19 pandemic in the US have included business closures, job losses, and high unemployment. Nationwide, unemployment rates rose to $14.7 \%$ in April and have not yet returned to pre-pandemic levels. ${ }^{1}$ Poverty rates have risen from $9.3 \%$ in June 2020 to $11.7 \%$ in November $2020 .^{2}$ Attempts to reduce viral spread included prolonged school closures, ${ }^{3}$ which place significant stress on families, especially those who do not have resources to organize alternate forms of childcare. The pandemic itself has increased stress levels for nearly everyone.

Associations between poverty and child maltreatment have been previously reported, ${ }^{4}$ raising concern for a potential increase in child abuse during times of

Corresponding author: Sharmila Dissanaike

Contact Information: Sharmila.Dissanaike@ttuhsc.edu DOI: 10.12746/swrccc.v9i39.817 social and economic hardship, as we are currently experiencing. Concurrently, teachers are the most common reporters to Child Protective Services, ${ }^{5}$ so school closures may simultaneously have resulted in fewer early reports of child abuse, which may lead to missed opportunities for prevention before injuries become more severe, requiring emergency department visits and medical attention.

As the COVID-19 pandemic has negatively impacted many families and communities, there is growing concern for the threat of child abuse to vulnerable children across the nation. ${ }^{5}$ We sought to determine whether the confluence of pandemic-related social changes would result in an increase in child abuse cases severe enough to warrant emergency medical attention in the West Texas region.

\section{Methods}

Texas Tech University Health Sciences Center has the only American College of Surgery verified Level 1 
Table. Breakdown of Abuse Cases Based on Sex and Age

\begin{tabular}{|c|c|c|c|c|c|c|c|c|c|c|c|c|c|c|}
\hline & Year & $\begin{array}{c}\text { Abuse } \\
\text { Cases }\end{array}$ & Deaths & Males & Females & $\begin{array}{c}\text { Age } \\
\mathbf{0}\end{array}$ & $\begin{array}{c}\text { Age } \\
\mathbf{1}\end{array}$ & $\begin{array}{c}\text { Age } \\
\mathbf{2}\end{array}$ & $\begin{array}{c}\text { Age } \\
\mathbf{3}\end{array}$ & $\begin{array}{c}\text { Age } \\
\mathbf{4}\end{array}$ & $\begin{array}{c}\text { \% Ages } \\
\mathbf{0 - 4}\end{array}$ & $\begin{array}{c}\text { Ages } \\
\text { 5+ }\end{array}$ & $\begin{array}{c}\text { \% Deaths } \\
\text { From Abuse }\end{array}$ & $\begin{array}{c}\text { \% Under } \\
\text { 1 Year }\end{array}$ \\
\hline & 2015 & 12 & 0 & 6 & 6 & 7 & 2 & 1 & 1 & 1 & $100.0 \%$ & 0 & $0.0 \%$ & $58.3 \%$ \\
\hline & 2016 & 19 & 0 & 9 & 10 & 10 & 5 & 3 & 0 & 1 & $100.0 \%$ & 0 & $0.0 \%$ & $52.6 \%$ \\
\hline & 2017 & 17 & 1 & 9 & 8 & 7 & 4 & 1 & 2 & 1 & $88.2 \%$ & 2 & $5.9 \%$ & $41.2 \%$ \\
\hline & 2018 & 17 & 3 & 10 & 7 & 7 & 5 & 5 & 0 & 0 & $100.0 \%$ & 0 & $17.6 \%$ & $41.2 \%$ \\
\hline & 2019 & 18 & 0 & 12 & 6 & 9 & 5 & 1 & 1 & 2 & $100.0 \%$ & 0 & $0.0 \%$ & $50.0 \%$ \\
\hline & 2020 & 37 & 5 & 21 & 16 & 21 & 6 & 5 & 1 & 3 & $97.3 \%$ & 1 & $13.5 \%$ & $56.8 \%$ \\
\hline Totals & & 120 & 9 & 67 & 53 & 61 & 27 & 16 & 5 & 8 & $97.5 \%$ & 3 & & \\
\hline
\end{tabular}

Trauma Center and the only American Burn Association verified burn center in the West Texas region, serving a 250-mile radius of primarily rural communities; it receives a large proportion of patients from this region with severe injuries. We compared the rates of nonaccidental trauma in children during the COVID pandemic year 2020 compared to prior years back to 2015 . Cases were identified using the University Medical Center Trauma Registry and verified through Texas Child Protective Services.

\section{RESULTS}

There were 120 cases of child abuse admitted during this 5-year period; annual incidence ranged between 12-19 cases/year, prior to a steep climb to 37 cases in 2020 (Table). There were 5 deaths in 2020, which exceeded the total number in the past five years combined. The vast majority (97.5\%) of non-accidental trauma was in children below 5 years of age. Consistent with the previous five years, children under 1 year of age represented the largest proportion of child abuse cases, at 58\%. Between 2015-2017 incidents were divided equally between sexes, with a subsequent trend toward more boys affected; in 2020 there were 21 boys and 16 girls who were victims of abuse.

\section{Discussion}

There has been a sharp increase in child abuse cases in West Texas during the 2020 pandemic.
This indicates a need for heightened awareness of non-accidental trauma in all children presenting with injury during this time, especially those below the age of 5 years, and even more so in non-verbal infants below 1 year of age, who accounted for over half the cases. Outreach from educators, child welfare workers, and other professionals to families under psychological stress may be helpful in alleviating some of the triggers for this unfortunate increase in child abuse. ${ }^{6}$ As many schools are delivering their coursework online, and medical practices are delivering their care by telehealth to mitigate the spread of COVID-19, educators and healthcare professionals must remain vigilant in detecting signs of child abuse, despite the limitations of virtual interactions. ${ }^{5}$ This study presents a few limitations despite the strength of the results. Child abuse cases were only identified using the University Medical Center Trauma Registry, excluding the local and prominent hospital system of Covenant Medical Center. In addition, children were not being seen for well-child care as much during the COVID-19 pandemic. This may have decreased the opportunity to pick up sentinel injuries and may have underestimated the identification of child abuse cases by the Texas Child Protective Services. A recent article from the Morbidity and Mortality Weekly Report suggested that the trends in U.S. Emergency Department Visits related to child abuse and neglect decreased during the COVID-19 pandemic, but the percentage of such visits resulting in hospitalizations increased. $^{7}$ 
Article citation: Garcia H, Wyatt TG, Tucker A, Dissanaike $S$. Increase in child abuse injuries during the COVID-19 Pandemic in West Texas. The Southwest Respiratory and Critical Care Chronicles 2021;9(39):25-27

From: Department of Surgery (HG, TGW, SD), Texas Tech University Health Sciences Center, Lubbock, Texas; Trauma and Burn Service Department (AT), University Medical Center, Lubbock, Texas

Submitted: $2 / 14 / 2021$

Accepted: 4/5/2021

Reviewer: Patti Patterson MD, MPH

Conflicts of interest: none

This work is licensed under a Creative Commons Attribution-ShareAlike 4.0 International License.

\section{REFERENCES}

1. Employment Situation Archived News Releases. U.S. Bureau Of Labor Statistics Web site. https:/www.bls.gov/bls/ news-release/empsit.htm\#2020. Published 2021, January 8. Accessed.
2. Han J, Meyer B, Sullivan J. Income and Poverty in the COVID19 pandemic. 2020. https://www.brookings.edu/wp-content/ uploads/2020/06/Han-et-al-conference-draft.pdf.

3. Swaby A. School districts across Texas suspend classes over coronavirus concerns, prepare for online learning. 2020. https://www.texastribune.org/2020/03/12/fort-bend-houstonarea-isds-suspend-classes-texas-over-coronavirus/. Published 2020, March 12. Accessed 2021, January 09.

4. Cancian M, Slack K, Yang M-Y. The effect of family income on risk of child maltreatment. Institute for Research on Poverty 2010:1385-1410.

5. Rapoport E, Reisert H, Schoeman E, Adesman A. Reporting of child maltreatment during the SARS-CoV-2 pandemic in New York City from March to May 2020. Child Abuse Negl 2020:104719.

6. Lawson M, Piel MH, Simon M. Child maltreatment during the COVID-19 pandemic: consequences of parental job loss on psychological and physical abuse towards children. Child Abuse Negl. 2020;110(Pt 2):104709-104709.

7. Swedo E IN, Leemis R, et al. Trends in U.S. Emergency Department Visits Related to Suspected or Confirmed Child Abuse and Neglect Among Children and Adolescents Aged $<18$ Years Before and During the COVID-19 Pandemic January 2019September 2020. Morbidity and Mortality Weekly Report. https://www.cdc.gov/mmwr/volumes/69/wr/mm6949a1.htm 